Revista de Comunicación y Salud, 2020, Vol. 10, no 2, pp. 63-80

Editado por Cátedra de Comunicación y Salud

ISSN: 2173-1675

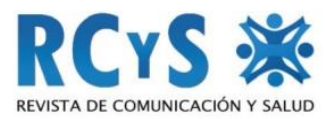

Enviado 15/08/2020

Aprobado 23/09/2020

\title{
CONSECUENCIAS DE UNA CRISIS SANITARIA. BOTIQUÍN DE IDEAS PARA COMPRENDER EL CORONAVIRUS Y SU TECNO-PANDEMIA INFORMACIONAL
}

\author{
Consequences of a Health Crisis. Ideas Kit for the Understanding of the \\ Coronavirus and its Informational Techno-Pandemic
}

\author{
José Antonio Marín-Casanova ${ }^{1}$ : \\ Universidad de Sevilla. España \\ jamarin@us.es
}

\begin{abstract}
Resumen
El coronavirus SARS-CoV-2, causante de la enfermedad COVID-19, ha generado una crisis sanitaria sin precedentes, la primera pandemia universal de la historia. Este fenómeno poco a poco está siendo explicado por la Ciencia. Pero no basta con explicar, también es preciso comprender. El objetivo principal perseguido aquí, desde la perspectiva metodológica de la Hermenéutica filosófica, es la comprensión de la crisis pandémica. Se analiza la metamorfosis que esta crisis está produciendo en las nociones de "realidad" y "subjetividad" y su repercusión en la Comunicación. Dos son los vectores destacados que vehiculan los resultados de esta reflexión: 1) la pandemia y la nueva normalidad hacen de la excepción la regla; 2) ello ha sido posible porque lo que inicialmente fue una mutación biológica se ha convertido en serie de conflictivas innovaciones disruptivas, que los gobiernos están controlando mediante medidas tecnopolíticas de disciplina social como el confinamiento doméstico. Así el coronavirus muta en tecno-virus informacional que se trasmite a través de los mass media y las redes sociales, infectando los cerebros humanos y provocando nuevos modos de pensar, actuar y vivir. A la pandemia se le solapa una infopandemia, cuyos daños mentales previsiblemente superarán los orgánicos. Se concluye entonces que no es la crisis sanitaria vírica la que está transformando la normalidad de la vida en la calle, sino las acciones tecno-políticas tomadas para afrontarla, aun cuando el reproche se lo lleve un coronavirus previamente tecno-personificado. Seguramente superaremos la pandemia, pero a costa quizá de que la info-pandemia definitivamente nos haya superado.
\end{abstract}

Palabras clave: biopolítica, comunicación, tecno-COVID-19, excepción, filosofía (hermenéutica), info-pandemia, nueva normalidad, salud pública, SARS-CoV-2, tecnopolítica.

1 José Antonio Marín-Casanova: Profesor Titular de Universidad en la USE de cuyo Depto. de Metafísica y Corrientes Actuales de la Filosofía, Ética y Fía. Política ha sido Director (2016-20). Es IP del Grupo PAIDI HUM326 ("CTS y Racionalidad Práctica"). Dirige la revista Argumentos de Razón Técnica. 


\begin{abstract}
The SARS-CoV-2 coronavirus, which causes COVID-19 disease, has generated an unprecedented health crisis, the first universal pandemic in history. This phenomenon is gradually being explained by science. But it is not enough to explain it, it is also necessary to understand it. The main objective pursued here is, from the methodological perspective of philosophical Hermeneutics, the understanding of the pandemic crisis. The metamorphosis that this crisis is producing in the notions of "reality" and "subjectivity" and its repercussion on communication is analyzed. There are two main vectors that lead to the results of this reflection: 1) the pandemic and the new normality make the exception the rule; 2) this has been possible because what was initially a biological mutation has become a series of conflicting disruptive innovations, which governments are controlling through technopolitical measures of social discipline such as domestic confinement. Thus, the coronavirus mutates into an information technovirus that is transmitted through the media and social networks, infecting human brains and provoking new ways of thinking, acting and living. An info-pandemic, whose mental damage is expected to exceed the organic damage. It can then be concluded that it is not the viral health crisis what is transforming the normality of life on the street, but the techno-political actions taken to confront it, even though the blame goes to the previously techno-personalized coronavirus. We will surely overcome the pandemic, but perhaps at the cost of the info-pandemic having overcome us once and for all.
\end{abstract}

Keywords: Biopolitics, communication, exception, techno-COVID-19, info-pandemic, new normal, philosophy (hermeneutics), public health, SARS-CoV-2, techno-politics.

\title{
Cómo citar el artículo
}

Marín-Casanova, J. A. (2020). Consecuencias de una crisis sanitaria. Botiquín de ideas para comprender el coronavirus y su tecno-pandemia informacional. Revista de Comunicación y Salud, 10 (2), 63-80. doi: https://doi.org/10.35669/rcys.2020.10(2).63-80

\section{INTRODUCCIÓN}

En los meses invernales de 2020 se ha extendido desde Wuhan en China a todo el mundo el virus SARS-CoV-2, causante de la enfermedad COVID-19, desencadenando la primera pandemia literal de la historia, tanto sanitaria como informacional. Los gobiernos de numerosos estados reaccionaron con medidas extremas, decretando en mayor o menor grado el confinamiento doméstico de casi toda la ciudadanía, suspendiendo más o menos restrictivamente las libertades e implementando medidas de control social de corte en mayor o menor medida autoritario. Otros gobiernos renunciaron, por el contrario, a la imposición de medidas limitadoras de la autonomía individual, lo que fue entendido por parte de la población y la opinión pública global como una desprotección y una falta de responsabilidad política.

Este primer confinamiento global de la historia o, en sentido casi literal, domesticación universal de la humanidad ha causado una crisis económica y social que

Revista de Comunicación y Salud, 2020, Vol. 10, n 2, pp. 63-80 
puede hacer pequeña la Gran Depresión que sucedió al Crac de 1929. Y ello dejando a un lado aparte que, como tantas voces influyentes han proclamado, esta enfermedad global habría de inscribirse en un contexto de mayor amplitud aún, como un efecto más de la "gran aceleración" del Antropoceno, ese nuevo periodo geológico, de intrínseca mediación tecnológica humana, caracterizado por una degradación tan ingente de la biosfera que nos lleva a un colapso exponencialmente probable no sólo de la civilización, sino incluso de la misma Humanidad en su conjunto.

Es algo más que un lugar común que la pandemia de la COVID-19 tiene a la humanidad en vilo, hasta el punto de que, aun cuando se logre superar, la vida humana en todo el planeta ya no volverá a ser igual. Supondrá un salto cualitativo para la comunidad. De hecho, la meta que se persigue ahora es la de alcanzar el oxímoron, popularizado por Justin Trudeau, consistente en la "nueva normalidad". El coronavirus nos ha sorprendido con las defensas bajas o, mejor dicho, sin suficiente inmunidad, y solamente se estará a salvo cuando, catalizada o no por una vacuna, se consiga la inmunidad comunitaria, de grupo u horda (herd immunity).

La vida ya sea individual o biológica, ya sea social o cultural, la vida, bien natural, bien histórica, se puede considerar como el éxito de un sistema inmunitario. Ésta es la premisa mayor de la inmunología general. Un sistema inmunitario es una defensa institucionalizada frente a una expectativa de daños en un tiempo. Ontogenéticamente la inmunidad biológica protege al organismo de la amenaza de la patológica iniquidad microbiótica. Sin embargo, "inmunidad" no es un concepto originario de la Medicina. Es un préstamo metafórico de etiología jurídico-política. Ya en Derecho Romano se reconocía la estricta interconexión entre communio e immunitas: la inmunidad refiere la protección legal a quienes ejercen significativos roles comunitarios. Antes que la inmunidad biológica está la inmunidad social: sin inmunidad no hay comunidad.

La inmunidad simbólica es decisiva para el animal humano en tanto que humano. Quizá constituya su diferencia específica. Los símbolos tienen una realidad puramente intersubjetiva e incluso, en la simbólica democrática, permiten inmunizar a los humanos de los intentos de algunos congéneres de imponer un sistema simbólico, siempre cultural, y, por tanto, contingente y sintomático, como si fuera natural y, por tanto, necesario y automático. El Derecho siempre es la expresión del nivel de inmunidad que alcanza una sociedad frente a la "injusticia", la formalización social del uso frente al abuso, el grado de solidaridad o apoyo mutuo contra el mal moral. Otro sistema inmunitario simbólico habitual es la Religión, canal histórico tradicional para indemnizar compensatoriamente los daños de la muerte.

Los sistemas inmunitarios, tanto biológicos como simbólicos, tienen en común trazar una neta divisoria entre interior y exterior, entre la vulnerable intimidad y la amenaza pública. Bien es cierto que las inmunidades naturales diferencian lo propio de lo extraño de un modo intrínsecamente "egoísta", sirven a individualidades, mientras que las sociales hacen esa diferenciación de un modo definitoriamente "altruista", sirven a comunidades. Tanto unos sistemas como otros pretenden diferir máximamente en el tiempo el daño, amparar al organismo ya individual ya social de la intemperie. Las

Revista de Comunicación y Salud, 2020, Vol. 10, no 2, pp. 63-80 
sociedades humanas sólo pueden mantenerse en el tiempo si los individuos asumen que la inmunidad privada de su biología sólo puede ganarse en el seno de una coinmunidad social efectiva.

Ahora con la pandemia el homo sapiens está vivenciando un acontecimiento histórico de insólita singularidad, un gran desafío experiencial, en el que se está sometiendo a experimentum crucis a todo su sistema ecosocial. Es la puesta a prueba de la normalidad de la especie: todas nuestras instituciones políticas, económicas, sociales y culturales se ven retadas por la enfermedad: el coronavirus COVID-19 subitáneamente ha puesto en crisis todas las esferas y escalas de la vida humana sin lugar a excepción. La excepcionalidad del momento, la condición de acontecimiento único de la alerta sanitaria global aconseja el ejercicio prudente de la calma filosófica frente al mayor test de resistencia jamás soportado por la especie humana. El tiempo recio solicita el pensamiento pausado y tranquilo que nos permita tanto repensar morosamente categorías y certezas heredadas como forjar nociones y abrir veredas que nos ayuden, al lado de las necesarias explicaciones científicas, a comprender libremente lo que está ocurriendo y a encarar con claridad el porvenir de la humanidad. Se trata, dentro de la koiné hermenéutica característica de la reflexión filosófica actual, de interpretar la "nueva normalidad" (el nuevo término mainstream mundial), de dotarnos de las herramientas intelectuales que nos permitan el tránsito de juzgar un pleonasmo la "antigua normalidad" a no considerar ya como oxímoron (si acaso como eufemismo) la "nueva normalidad".

Abundan practicantes profesionales de la Filosofía que, a partir de puntos de vista diversos, han empezado a publicar artículos, libros y videogramas, mediante los que ensayan el análisis de la novedad del acontecimiento. Se han prodigado de forma virtual coloquios y debates filosóficos en línea sobre la enfermedad global. Al hecho inaudito de la plaga mundial le está correspondiendo una conciencia del hecho asimismo mundial. Es esta la oportunidad de la puesta en común en redes telemáticas de inquietudes y sospechas, de dudas y perplejidades, así como de ideas y creencias. La enfermedad global hace que precisemos de nuevos instrumentos de reflexión, de un laboratorio de pensamiento y comunicación, o más modestamente, de un botiquín conceptual, para así empezar a resignificar nuestras relaciones con la biosfera, con la antroposfera, con la tecnosfera e incluso con nuestro propio cuerpo y lo que nos quede del "alma", con la vida y su salud. La nueva normalidad nos obliga al abandono definitivo del paradigma natural (la naturaleza no nos va). Si la normalidad puede ser nueva, es que no es natural, sino cultural. La "normalidad" tiene tiempo, es histórica y técnica, puesta en el tiempo, hecha. Es el tiempo de la nueva normalidad, de hacer normalidad.

Se abre aquí en toda su amplitud y en máxima tensión el arco de la racionalidad práctica. En efecto, en lo que respecta a homo sapiens, "normal" ya no podrá ser, en primera acepción del DRAE, aquello "que se halla en su estado natural", sino que, antes al contrario, en segunda acepción del DRAE, se ajusta a ciertas normas fijadas de antemano. En "las normas fijadas de antemano" resuena, en clave de razón práctica, la construcción social de la normalidad. El socioconstructivismo apoya esta teoría al

Revista de Comunicación y Salud, 2020, Vol. 10, n² 2, pp. 63-80 
entender que todo conocimiento es construido a través de la interacción del individuo con la sociedad y su ambiente y, por tanto, la normalidad sería otra idea construida en el marco de esta interacción. De esta manera, no se podrá hablar de normalidad en general, sino de normalidad dentro de una sociedad y un contexto en concreto. Se puede decir, por tanto, que la normalidad es un constructo social que engloba los comportamientos, ideas y características que se adaptan a la vida en sociedad. Una suerte de autorregulación social.

La crisis, inicialmente sanitaria, tiene asimismo una dimensión filosófica sin cuya atención la podremos explicar, pero no comprender. Comprender la pandemia exige percatarse de la variada panoplia de sus implicaciones ontológicas, gnoseológicas (englobando las retórico-discursivas), y axiológicas (ético- políticas, y, en último término antropológicas). Y ello no puede menos que ser así, cuando nunca un acontecimiento natural, incluido el Terremoto de Lisboa de 1755, había conmocionado tanto la conciencia, no ya europea, sino hoy ya mundial. De hecho, todas las especialidades clásicas de la filosofía resultan ahora interpeladas por el coronavirus y se ven compelidas a enfrentarse conceptualmente a la "nueva normalidad" exigida por su pandemia.

\section{LA INTERPELACIÓN ONTOLÓGICA}

Markus Gabriel, sostiene que "El orden mundial previo a la pandemia no era normal, sino letal" (ASPO, 2020, p. 133), nuestro siglo ya era una pandemia, resultante de la globalización. La "pandemia" por su etimología afecta a todo el pueblo. Todo el pueblo es la humanidad entera sin distingos de fronteras, de ahí lo absurdo de los confinamientos nacionales. No se trata, pues, de una enfermedad infecciosa cualquiera. La cuestión es si no se tratará de "una respuesta inmune del planeta a la insolencia del ser humano, que destruye infinitos seres vivos por codicia" (p. 131). Este planteamiento, además de permitir al autor concienciarnos, como buen Linker, de que la cadena infecciosa del capitalismo global "destruye nuestra naturaleza y atonta a los ciudadanos de los Estados nacionales para que nos convirtamos en turistas profesionales y en consumidores de bienes cuya producción causará a la larga más muertes que todos los virus juntos" (p. 134), le permite denunciar la ideología que asocia como un automatismo progreso tecnocientífico y progreso socio-moral. Por ello "Necesitamos una nueva llustración, todo el mundo debe recibir una educación ética para que reconozcamos el enorme peligro que supone seguir a ciegas a la ciencia y a la técnica" (p. 133). Es imprescindible entonces para salir de la crisis una "conciencia filosófica", que nos convierta en "cosmopolitas de una pandemia metafísica" (p. 134).

Ciertamente, los virus plantean un problema metafísico. Y es que ni siquiera se sabe a ciencia cierta qué son, cuál es su estatuto ontológico. Los virus comprometen la misma noción de vida, que es plural, pues no se puede afirmar ni negar tajantemente que sean seres vivos propiamente. Desde luego, es éste un problema de la Biología, pero más allá de la solución que esta ciencia pueda aportar, el coronavirus nos devuelve el problema metafísico de la omnipotencia, o como diría Hans Blumenberg, del "absolutismo de la realidad". Parecíamos haber olvidado que la realidad es, que hay

Revista de Comunicación y Salud, 2020, Vol. 10, n 2, pp. 63-80 
realidad y que el humano está religado a ella, por más que pretenda suprimirla para hacerse un mundo a medida suya, como ciertos delirios de la impenitente ala wishful thinking del constructivismo nos auguraban.

Por supuesto, que la realidad es una construcción. La noción de realidad se nos dirá en seguida en afán de precisión. Sea. Pero los humanos nunca vivimos en la realidad, sino en una descripción de la realidad. No habitamos el mundo sin más, sino en un mundo comprendido, en una determinada interpretación del mundo. Este dato de la koiné filosófica contemporánea, este dato que suelen compartir hoy los filósofos, a muchos ha llevado en hiperbólica ingenuidad constructivista a preterir el out-there. Es cierto que el impacto neo-tech en lo real ha materializado el crepuscular dictum nietzscheano según el cual "el mundo verdadero se hizo, por fin, fábula". Pero una cosa es hacer problemática, como Nietzsche, la distinción metafísica entre verdad y fábula, fabulizar la verdad, y otra muy distinta es poner la fábula en el lugar de la verdad y manteniendo las características fuertes de esa verdad, "verificando" entonces la fábula.

En efecto, no es lo mismo caracterizar el efecto ontológico de las nuevas tecnologías, que hace que lo real analógico se supedite o se haga funcional a lo virtual digital, como nosotros mismos hemos hecho a menudo, que atribuir a lo virtual los predicados de la vieja realidad, llegando a suprimir lisa y llanamente el "mundo externo", desde la res extensa cartesiana al mundo 1 popperiano. Y así, cuando se daba por sentado que lo virtual era ya lo realmente real, llega un virus con el que la "naturaleza" llama a la puerta de casa para recordarnos con sus golpes que existe, depotenciada y vulnerable, sí, pero naturaleza. Al "orgullo" filosófico la experiencia de la pandemia viene a suponerle como un memento mori de la confusión intelectual entre pensamiento según el deseo y realidad, un aldabonazo recordatorio de nuestra impotencia y finitud, de nuestra contingencia.

Lo real se nos manifiesta subitáneamente bajo la especie de un desconocido agente patógeno. Su pequeñez microscópica, que lo hace indetectable para los sentidos humanos, exhibe paradójicamente la grandeza de la resistencia de la naturaleza a los experimentos del aprendiz de brujo humano. Byun-Chul Han, en "La emergencia viral y el mundo de mañana" (ASPO, 2020, pp. 97-111), apela también al viejo concepto de "resistencia" al reparar en la dimensión metafísica de la pandemia, en la "apatía hacia la realidad". La digitalización de la sociedad nos había dado la impresión de haber cancelado la resistencia ofrecida por la realidad. Es como si, gracias al virus, cuya pandemia nos vendría a hacer culpables, toda vez que "es resultado de la crueldad humana", de que "intervenimos sin piedad en el ecosistema sensible", descubriéramos de repente que existe "el afuera", un exterior a nosotros mismos y fuera de los mundos que habitábamos digitalmente alienados, que se resiste a nuestra agresión.

Con el fin de "repensar y restringir radicalmente el capitalismo destructivo, y también nuestra ilimitada y destructiva movilidad, para salvarnos a nosotros, para salvar el clima y nuestro bello planeta" (p. 111), tributo de pago casi imprescindible a la industria editorial para publicar, Han apela a su tesis del exceso de positividad de las sociedades occidentales y su mundo globalizado sin fronteras. Esa mala costumbre occidental que

Revista de Comunicación y Salud, 2020, Vol. 10, n 2, pp. 63-80 
ha prescindido en su imaginario de enemigos externos no podía, ni mucho menos, temer el contagio de un patógeno como el coronavirus. Occidente se había creído invulnerable eliminando de nuestra vida la negatividad de lo real, justo lo que el virus resistente rescata: el pánico desmedido al virus "es una reacción inmunitaria social, e incluso global, al nuevo enemigo. La reacción inmunitaria es tan violenta porque hemos vivido durante mucho tiempo en una sociedad sin enemigos, en una sociedad de la positividad, y ahora el virus se percibe como un terror permanente" (p. 108).

Ahora bien, pese a todo, nosotros seguiremos partiendo de que el factum de nuestro tiempo es el hecho neotecnológico y su "abolición" de la (noción de una) naturaleza (absoluta o incondicionada y necesaria, omnipotente $e$ invulnerable, horizonte insuperable de la acción humana). Así que la respuesta a la pregunta de si no se estará vengando la naturaleza de intelectualillos del tres al cuarto es que no. Y la razón es fácil de exponer. En efecto, dejando a un lado que es insoslayable que la crisis del coronavirus nos tapa la boca con mascarillas a los bocazas más o menos pretenciosos que pontificamos alegre y ligeramente sobre lo divino y lo humano, una lección moral que no vamos a olvidar tan fácilmente, y con independencia también de la hipótesis de aspecto descabellado acerca de que este virus ha sido creado en un laboratorio, con intención dolosa, según la versión del diario The Washington Post, o sin esa intención, por mero accidente, según la versión del Premio Príncipe de Asturias y PremioNobel Luc-Antoine Montaignier, es decir, aun asumiendo la total naturalidad del surgimiento del coronavirus, el caso es que en la materialización de su nocividad potencial es insoslayable la mediación tecnológica. Sin la sociedad de masas y sin la globalización planetaria, fruto ambas instancias del sistema técnico, que da alas supersónicas al transporte de mercancías y personas, el coronavirus no habría podido convertirse en el flagelo pandémico que es hoy.

La damnificación pandémica requiere necesariamente de la "prótesis" tecnológica para su eficacia operativa. Y es muestra conspicua del dato ontológico en que se asienta el llamado "fin de la historia": la supresión del límite. Cuando todavía había historia (tiempo con sentido, consentido por y para una finalidad) había límite, un límite que se consideraba "natural" y ante el que rebotaba, cual irrebasable muro vertical, toda acción humana, teórica, práxica o técnica. Se discutía qué limite había, si el límite era cosmológico, teológico, o antropológico, pero no se discutía el que lo había, que había límite. Hoy, en cambio, lo que no admite discusión es la supresión del límite. La Tierra aparece como depósito ilimitado de la acción técnica. Por eso la salida de la crisis de la pandemia, si la hay, no está en volver a entrar en una historia que sin límite natural no se puede dar ya, sino en la autolimitación posthistórica, la autorregulación tecnológica.

$Y$ es que en la nueva normalidad el tiempo ya no es vivenciado como natural (cíclico o cosmológico) ni histórico (lineal o antropoteológico), pues ya no es normal que la nueva vida, digital o numérica, presente perfil cualitativo. Se observa un tiempo meramente cuantitativo como flujo "insignificante" de quanta instantáneos, sin horizonte que los integre en una trama histórica de sentido. La nueva normalidad no parece tener Historia: la memoria "normal" hoy es externa y el individuo crecientemente carece de capacidad de concentración. En el imaginario de la autocomprensión humana la (nueva) Tecnología ha absorbido a la Historia que en su tiempo "normal" había 
absorbido, a su vez, en el proyecto intencional de la humanidad, la "normalidad" de la Naturaleza. La nueva normalidad es antropocénica.

\section{LA INTERPELACIÓN GNOSEOLÓGICA}

Hace un par de años aparecía un libro cuyo título ha contribuido a preparar la "nueva normalidad", El fin de la normalidad. La gran crisis y el futuro del crecimiento. Su autor era el hijo de John Kenneth Galbraith, James K. Como en el despertar de un largo sueño, la crisis iniciada en 2008 nos confrontaría con una situación de incertidumbre, que parece haberse convertido en permanente. Si bien los políticos y los expertos continúan con su letanía de la vuelta a la normalidad, ese mundo que conocimos de recursos abundantes y baratos, de crecimiento sostenido y regular, habría quedado atrás sin visos de volver. La ciencia económica y sus ideas naturalizadas de equilibrio y crecimiento ya no pueden dar cuenta de una economía sometida a un sistemático saqueo financiero y a una estructura de costes fijos heredada de los tiempos de la energía barata. Esta tesis del libro la repite en 2020 en "La movilización que ha de empezar ahora". Aunque el enfoque sigue siendo de Economía, Galbraith parte de una constatación que podríamos decir compromete lo que podríamos denominar el futuro del conocimiento y es la catástrofe conceptual: "Un mundo entero de ilusiones, autoengaños y sofismas ha muerto".

Con independencia del entusiasmo intervencionista con el que Galbraith pareciera no querer volver a la normalidad por ser la normalidad el problema, lo cierto es que, desde el punto de vista epistemológico, una nueva realidad exige una nueva batería de categorías con que concebirla. Los conceptos están para categorizar la experiencia y resulta que, como ha dicho Emilio Lledó, refiriéndose a la situación actual, ésta es una situación antes "inexperimentada". Entrevistado, explica que la crisis del coronavirus es una gran oportunidad para salir de la caverna de Platón, para el cultivo de la inteligencia crítica. Como el prisionero de la caverna, frente a la pandemia podemos preguntarnos: "quién nos dice la verdad, quién nos engaña, quién quiere manipularnos". El pensamiento crítico es idóneo para prevenir otras amenazas pandémicas como "el deterioro de la educación, de la cultura y del conocimiento". Siempre el conocimiento.

Más allá de los problemas que el conocimiento virológico, biológico y médico puedan encontrarse a partir de la vieja cuestión taxonómica de la naturaleza de los virus, en general, y la del SARS-CoV-2, en particular, cuestiones en principio "científicas", la crisis actual nos confronta con problemas gnoseológicos relativos a la comunicación y la salud atingentes a la veracidad de la información, a la cuestión de la infoxicación y la posverdad. Autores filosóficos como Žižek en "El coronavirus es un golpe al capitalismo a lo Kill Bill y podría conducir a la reinvención del comunismo" (ASPO, 2020, pp. 21-28) - Badiou en "Sobre la situación epidémica" (ASPO, 2020, pp. 67-78), como si estuvieran respondiendo al interrogante de Lledó, se lanzan a la crítica de las redes sociales para reivindicar la orientación polar de la ciencia en estos tiempos recios. El propio Žižek reverdece la pregunta marxiana acerca de dónde terminan los hechos y dónde comienza la ideología. Sin embargo, tienen más interés crítico las posiciones minoritarias de reserva ante la opinión de los expertos científicos y sus comités.

Revista de Comunicación y Salud, 2020, Vol. 10, nํ2, pp. 63-80 
La reserva de Gabriel ya antes la hemos expuesto de pasada: la ciencia por sí sola no puede superar la crisis, tanto la del coronavirus, en particular, como, en general, la de un orden mundial letal del que es expresión la misma pandemia. Veamos mejor la reticencia de Giorgio Agamben, autor también de otro libro "profético", La comunidad que viene, que sostiene que, desde los inicios de la civilización occidental, la fuente de la soberanía del poder político se encuentra en un doble movimiento que permite excluir la vida biológica de la ley e introducirla al mismo tiempo mediante el estado de excepción. Así como en 1986 sosteníamos "el mito de la ciencia", Agamben mantiene hoy que la ciencia es la religión de nuestra época. Y así aún en febrero, el día 26, llegó a escribir, es el título de su texto, sobre "La invención de una epidemia" (ASPO, 2020, pp. 17-19). Considerar el fenómeno vírico que está azotando a la humanidad, que ni peste bíblica la hubo peor, como una especie de gripe, puede ser una típica metedura de pata intelectual, una hipérbole filosófica tristemente ridícula. Sin embargo, pone el dedo en la llaga del hecho de que la ciencia y la política forman un entreverado inextricable, de que, como sabemos desde Bacon por lo menos, el saber es poder, pues es funcional a él, una función del poder. Luego los problemas gnoseológicos son también políticos. Y su resolución es un acto político. En este sentido, que la epidemia sea "invención" no significa que no exista, sino que su definición es política. Sirva el ejemplo tosco de la obligación de cubrirse con mascarilla un día no y otro sí, un día sí y otro no. A partir de las doce de la noche la carga vírica ambiental no es significativamente más o menos onerosa que un minuto antes, pero sí la multa que se puede recibir.

Agamben denunció las medidas "frenéticas, irracionales y completamente injustificadas" que estaba tomando el gobierno de Italia como respuesta al "clima de pánico" fomentado por el propio gobierno y la caja de resonancia mediática. Por muy precipitado e inoportuno que fuera su artículo, y dejando atrás el marco peninsular itálico, no deja de tener relevancia filosófica el señalamiento de la tendencia de ciertas instancias gubernamentales a hacer del estado de excepción, al socaire de la excepción coronavírica, el "paradigma normal de gobierno". Lo cual a su vez alimenta el hecho de estar acostumbrándonos a vivir con miedo. Necesitamos "estados de pánico colectivos". La lógica es diabólicamente perversa: "la limitación de la libertad impuesta por los gobiernos es aceptada en nombre de un deseo de seguridad que ha sido inducido por los mismos gobiernos que ahora intervienen para satisfacerla" (p. 19).

Haber traído a colación ese primer texto de Agamben (luego vendrían dos más) sobre la crisis del coronavirus nos sirve no sólo para evidenciar críticamente los límites epistemológicos del criptopositivismo latente o posivitivismo patente en los que elpidológicamente ponen la anhelada salvación del mal en la ciencia, sino que también nos sirve como exponente de otro gran efecto gnoseológico de la pandemia que puede resultar mucho peor que ella: la infodemia. En efecto, más dilatada que la pandemia, la nueva normalidad afronta una tecno-pandemia de incidencia creciente (Echeverría y Sánchez Almendros, 2020, pp. 443-454). El tecno-virus es una tecno-persona idónea. Se trata de una tecno-persona que no es de carne y hueso, sino pura representación tecnológica y mediática. Esta tecno-persona se ha instalado viral y profundamente en el imaginario social de nuestra época, del que no será evacuada, por más que la

Revista de Comunicación y Salud, 2020, Vol. 10, nº 2, pp. 63-80 
pandemia sea controlada e incluso exterminada. Tecno-COVID-19 configura ya la memoria -y el ejercicio del poder- de nuestro tiempo.

En efecto, ya la tecno-persona tiene características compartidas con los virus. El tecno-virus lo que hace es hipertrofiar esas características y, como info-virus, pandemizarlas. Así como los virus no son individuos, sino cepas, como las bacterias, y dependen completamente del entorno y para adaptarse a él y reproducirse, mutan genéticamente generando nuevas cepas, y así como carecen de conciencia y, en consecuencia, también de intenciones, ni tampoco son sujetos semovientes, sino que otros agentes los mueven, como las personas que son sus vehículos y los llevan de un lado a otro arracimadas en medios de transporte, tanto particulares como colectivos, de modo masivo, pero aleatorio, sin intencionalidad ni mucho menos conciencia moral, así ocurre con las tecno-personas. La tecno-persona no tiene nada que ver con la persona tecnologizada como vulgarmente se podría creer, pues de entrada ya, la tecno-persona, a diferencia de la persona, no tiene conciencia. La tecno-persona, para Echeverría y Almendros (2020, pp. 81-132) es, antes al contrario, un concepto filosófico general, para designar entidades informacionales, más o menos ligadas a las personas humanas o corporativas de las que surgen, alojadas en las diversas "nubes" digitales, que son centros de almacenamiento y gestión de datos con naves de ordenadores de capacidad superlativa. Aún a riesgo de simplificar, las tecno-personas se conciben como sistemas de datos, los cuales convenientemente procesados, bajo una determinada aplicación tecno-lógica, presentan forma humana simulada en los monitores de los distintos dispositivos electrónicos computerizados. Cualquier usuario de smartphone que entra en las nefelibatas redes sociales digitales genera ya, puesto que en el mundo digital o tercer entorno la identidad es cambiante y plural, varias tecnopersonas. Las "nubes", principalmente las cuatro más ricas del mundo por su capitalización en Bolsa, Google, Apple, Facebook, Amazon han desempeñado un papel importantísimo en la difusión del tecno-virus asociado a COVID-19, al que Echeverría y Almendros denominan tecno-COVID-19 (p. 443). También los medios de comunicación de la época industrial (prensa, radio, televisión, etc.) han contribuido mucho a difundirlo, sobre todo, dado el confinamiento casero obligatorio.

En cualquier caso, las tecno-personas no se mueven por sí mismas, sino que son movidas por otros agentes, sea mediante instrucciones de cómo comportarse y qué gestos hacer ante las cámaras, sea mediante programas informáticos que transmiten por vía digital, nos demos cuenta o no, dadas las muchas cámaras ocultas, las cookies o los sistemas de geolocalización que envían todos nuestros datos a las nubes, para su custodia y tratamiento. Análogamente proceden los epidemiólogos con los datos de COVID-19, sin que el virus se entere. Así como los Señores del Aire o ahora Señores de las Nubes pueden prever nuestros comportamientos, los epidemiólogos pronostican la eventual evolución del coronavirus. De este modo se construyen las tecno-personas, sean de índole política, social o vírica. Las redes globales de información y datos generan a diario millones de tecno-personas posibles, incluidas las que se nos asignan como usuarios. Esas tecnologías se han aplicado masivamente a COVID-19, que se ha convertido en la entidad informacional más mencionada en los mass media "tradicionales" y en las "nuevas" redes sociales mundiales, haciéndose viral de

Revista de Comunicación y Salud, 2020, Vol. 10, № 2, pp. 63-80 
inmediato, un infovirus. Ya hace tiempo que es la tecno-persona más relevante del tercer entorno. Las tecno-personas, como la epidemia de Agamben, pueden ser ficciones, casi siempre lo son, pero generan realidades como el dinero, ¡la mayor ficción! Las tecno-personas median entre los cerebros electrónicos y los orgánicos. Cuando entran por los ojos de las personas a través de las pantallas digitalizadas impregnan las mentes humanas. Casi siempre las contaminan. Así es como se ha generado un tecno-virus informacional a partir del coronavirus. Echeverría y Almendros (2020) mantienen la hipótesis de que a la pandemia actual se le ha superpuesto una infodemia, es decir, una epidemia informacional que afecta intensamente a millones de humanos. Y también pronostica que los daños mentales son y serán mayores que los males orgánicos suscitados por el coronavirus, por muy dramáticos que estos sean. Crisis sanitaria aparte, vienen profundas crisis económicas, sociales y políticas, cuyo conjunto configura los imaginarios tecno-COVID-19.

La ingente masa de datos, ciertos o no, surgida a partir del virus, como el propio artículo de Agamben, han creado una tecno-persona vírica, que tiene nombre e imagen global, con millones impactos. La implementación informacional de COVID-19 por diversas organizaciones tecnocientíficas, como la misma OMS, ha convertido una entidad biológica en una compleja cepa informacional y tecnológica: tecno-COVID-19. Echeverría y S. Almendros la califican de tecno-persona vírica (p. 453), porque tiene un virus como origen, pero por su estructura y funcionamiento es muy similar al resto de tecno-personas de nuestro tiempo. De hecho, como las tecno-personas, es plural: no es uno, sino muchas variantes de sí mismo. Conforma tecno-virus informacionales que se trasmiten a través de los mass media y las redes sociales, casi siempre con el resultado de incidir y transformar el modo de pensar y de comportarse de las personas, tanto físicas como jurídicas. Por eso se trata de una tecno-persona, una tecno-naturaleza que genera diversos tipos de males, aparte de los físicos y orgánicos que, de acuerdo con su naturaleza plural, el propio virus genera. Anida en los cerebros humanos y los trasfigura, generando nuevos modos de pensamiento, acción y vida. Su incidencia es creciente, hasta el punto de que la infodemia está más extendida que la epidemia. Además de una pandemia, sufrimos asimismo una tecno-pandemia.

La infodemia pone de relieve el problema de la comunicación de la información, pues variantes del tecno-virus informacional han sido mentalmente muy tóxicas, dado que han generado creencias y comportamientos harto irracionales en amplios sectores sociales. Se hipertrofia la cuestión epistemológica del lenguaje como vehículo del conocimiento y nos vemos obligados a hacernos cargo, como descubrió el giro lingüístico del pensamiento, de que no hay un lenguaje neutro desde el que comunicar los hechos, pues el lenguaje mismo interviene en la constitución de los hechos. Lo que llamamos "realidad" es el resultado de troquelar lingüísticamente el out-there: el lenguaje recorta los hechos, que por eso mismo no son dados (pasivamente), sino hechos (activamente): los "datos" son "hechos". Y si esto es así, entonces la retórica deja de ser algo adjetivo, para adquirir un peralte substantivo.

La retórica de la comunicación aparece como campo de Marte en la batalla de la opinión pública, y nunca mejor dicho, dada la preferencia de los gobiernos y los agentes 
sociales, como patronal y sindicatos, por el empleo de la metafórica bélica a la hora de comunicar la crisis hodierna de salud: "estamos en guerra contra el coronavirus", dando un paso adelante en la tecno-prosopopeya social del coronavirus, presentado como el hostis común, el enemigo público número uno, cuya tecno-imagen de indeseable social, por cierto, está claramente inspirada en la manida iconografía de alienígenas (¡los marcianos de los años de la guerra fría!). Recordemos al Jemad Villaroya tecnoordenando ante las cámaras que, frente al coronavirus, "todos somos soldados". Se trataba de un acto de comunicación tecno-política en la que el coronavirus SARS-CoV-2 estaba siendo concebido como una tecno-persona a la que habría que pasar por las tecno-armas. El estado de alarma se convertía así en "estado de guerra". Y con este hashtag de llamada a la movilización general \#EsteVirusLoParamosUnidos en el Twitter gubernamental el estado de guerra se ha hecho Estado de propaganda para uniformar a la población, más súbdita que ciudadana, dada la suspensión de derechos convalidada en un parlamento, vale decir, disfónico, y mandarla confinada a casa, caso paradigmático de acción tecno-política de autoritario efecto social total. Alguien podría plantearse si el lenguaje bélico es sólo una metáfora inocente para ilustrar la situación o describe fielmente la realidad. La cuestión, sin embargo, es que ni hay "metáfora inocente", ni tampoco "descripción fiel de la realidad", toda vez que es la metáfora lo que vehicula la (llamada) "realidad".

Eso explica que los puntos de vista difieran aquí entre los distintos autores, el empleo general del lenguaje bélico no obedece a las mismas razones. Por ejemplo, para Agamben ese lenguaje vendría dado por un estado de excepción decretado sin justificación por el Estado, de modo que, si hubiera que hablar de guerra, sería de una guerra civil, donde el enemigo, absurdamente invisible, estaría ahora en nuestro propio interior, mientras que para Badiou (ASPO, 2020, p. 74), al analogar epidemia y guerra, la retórica bélica se corresponde perfectamente con un proceso mortal de encrucijada entre la naturaleza (el virus) y la sociedad (el estado nacional). Pero no todo es una pugna entre dos ejércitos: una horda de minúsculos y escurridizos patógenos, popularmente conocidos como coronavirus, y una sublime legión de células y moléculas especializadas en exterminar a los invasores, el sistema inmunitario, que la acabará ganando con la "moral de victoria" invocada por el Presidente Pedro Sánchez, pues, además de la bélica, también tenemos una metafórica específicamente de la inmunidad. Roberto Esposito lleva bastantes años hablando ya de que vivimos bajo un paradigma inmunológico, y en relación con el coronavirus ha hecho extensiva su tesis en varios artículos publicados durante lo que va de pandemia. Así en Inmunitas, se había referido de hecho a la lucha contra un brote epidémico como un acontecimiento, entre otros, que debe entenderse como una respuesta de protección ante un peligro. En un artículo sobre Biopolítica y coronavirus, Esposito (2020a) refiere las "prácticas profilácticas" que están poniendo en evidencia tanto "el síndrome inmune real" del nuevo régimen biopolítico como la misma fortaleza del sistema inmunitario de la sociedad. El paradigma inmunológico muestra su vigencia también en la oposición a la inmigración ilegal o en las medidas para neutralizar el último virus informático.

Sin embargo, Han (2012, p. 18), le niega la mayor a Esposito, considerando que "el paradigma inmunológico no es compatible con el proceso de globalización". La otredad

Revista de Comunicación y Salud, 2020, Vol. 10, n² 2, pp. 63-80 
inmunológica ha sido sustituida por la diferencia posmoderna, que "ya no genera ninguna enfermedad". Sustenta así la tesis de la sustitución de la época viral por una época neuronal. Con la irrupción de la pandemia Han ha explicado la violenta reacción inmunológica suscitada (para burla de Žižek, 2020b) como la confirmación de que nos habíamos acostumbrado a vivir en un mundo sin graves amenazas exteriores, en una sociedad de la positividad. Las sociedades occidentales están reaccionando de forma exagerada porque se estaban acostumbrando a vivir sin enemigos abiertos y tolerantes, sin mecanismos de inmunidad, por lo que cuando surgió una amenaza real entraron en pánico, por lo que "el virus se percibe como un terror permanente".

Afloran como nunca las emociones con la pandemia y con las emociones, que para muchos, seguidores, quizá sin saberlo, de Sócrates, es menester sujetar racionalmente para que haya un criterio de verdad, el más clásico de los problemas gnoseológicos, que en términos de Comunicación se plantea hoy como el problema de la posverdad. La posverdad es la forma contemporánea de la verdad. La crisis de la COVID-19 ha traído, para siempre ya, la crisis de la verdad, pues ha quedado de manifiesto definitivamente cómo la verdad no puede establecerse al margen del poder. La pandemia ha dejado claro que la verdad en nuestros días se presenta intrínsecamente hipermediada: no hay verdad al margen de los medios que la comunican y su efecto código. Que la verdad venga mediada por los media, nunca mejor dicho, indica que por grande que sea la pretensión de separar la ciencia de la potencia, el saber del poder, resulta genuinamente ingenuo preterir que los que dicen dedicarse a ver el orden de las cosas, la "normalidad", el saber, se dedican más bien (a ver) cómo poner orden en las cosas, la "nueva normalidad", el poder. Quizá sea mérito del coronavirus el haber desenmascarado cómo la humanidad en su praxis cotidiana ha preferido siempre cambiar la realidad, o sea, el poder, a conocerla, o sea, a la verdad. Y si la humanidad, cuando se dedica a entender las cosas, lo hace con la esperanza de controlarlas, entonces no hay diferencia ni puede haberla entre verdad y posverdad. La verdad después de la disrupción pandémica es más intersubjetiva que nunca, ni objetiva ni subjetiva, política. Por ello en la "nueva normalidad" la verdad será retórica o no será.

\section{LA INTERPELACIÓN AXIOLÓGICA}

Dejando a un lado el pandémico "buenismo moral", la moralina que ha proliferado extendiéndose a la par que el coronavirus, tanto con trasnochados llamamientos flower power al "buen rollito", valga el coloquialismo de la expresión, como también con su versión grave, que hace del filósofo una especie de funcionario moral de la humanidad, versión laica del santo occidental y del santón oriental, lo cierto es que no podemos aplazar más, como nos urgía el asunto mismo de la posverdad, la dimensión prácticoracional de la crisis sanitaria mundial, sus implicaciones ético-políticas, axiológicas, en donde desembocan las ontológicas y las gnoseológicas vistas hasta ahora. De hecho, casi todos los autores que se han pronunciado sobre la plaga han terminado haciendo consideraciones dentro del ámbito de la Ética y la Filosofía Moral y Política dejando impartida su lección moral. 
Ya hemos visto que Markus Gabriel reclamaba una educación ética para evitar el dañino automatismo de identificar progreso moral y progreso tecno-científico y lograr una conciencia moral una para una humanidad una. "El virus nos dice entonces complementaría Morin, 2020- que esta interdependencia debe dar lugar a la solidaridad humana en la conciencia de nuestro destino común". La posición de Žižek es quizá la más moralista y, al menos, hay que agradecerle su sinceridad y franqueza en el planteamiento y reivindicación de un comunismo cuya única alternativa, así lo cree él, es la barbarie, toda vez que necesitamos "una solidaridad incondicional total y una respuesta coordinada globalmente, una nueva forma de lo que una vez se llamó comunismo" (2020a). Olvida Žižek que antes de llamar a la solidaridad cooperativa global se necesita una comunidad, la cual precisa, a su vez, de coinmunidad. Antes del comunismo debe darse, por utilizar un término de Sloterdijk, el coinmunismo.

Más calado tiene la reflexión de Agamben en "Contagio" (ASPO, 2020, pp. 31-33), que ve como implicación moral del confinamiento la supresión de la otredad: "Nuestro prójimo ha sido abolido" (p. 33). O patologizado (el croata Horvart (2020) habla de que el otro es construido ideológicamente en tanto enfermedad). O criminalizado (Darío Sztajnszrajber (2020), apunta que la mentalidad policial inducida en el ciudadano lleva a transformar al otro en un agente de contagio permanente: se criminaliza al sospechoso de estar contagiado). El miedo al otro generalizado, en definitiva. Con la irrupción de la COVID-19 y la digitalización de la vida confinada el cuerpo se considera universalmente como potencial agente patógeno y se rompe. Aparecen los "cuerpos rotos" (Puig Punyet, 2020). Una deriva antropológica de esta fobia a la otredad que se radicaliza con la crisis del coronavirus consiste en hacer del propio cuerpo alteridad. Tratar el cuerpo de uno como "otro", como otredad potencialmente patológica. El miedo se extiende así y pasa de tenerse a los demás a tenérselo también a uno mismo. A esta sospecha de uno mismo contribuye en la nueva normalidad la digitalización de la vida: los tecnocuerpos desplazan la carne, como si solamente fuésemos conciencia siempre disponible en remoto para el contacto sin cuerpo, el contacto (contagium) sin contacto, sin contagio (contagium), el tele-contacto, sin horas oficiales de descanso, sin fines de semana, sin vacaciones. El "nuevo" humano "normal" se relaciona, antes a través de pantallas que del cuerpo, como si careciera de cuerpo. Su potencial enfermedad convierte el cuerpo en un casi estorbo para la vida. Una vida que paradójicamente ya no es la propia, la de cada cual, sino la vida nuda. He ahí el valor que viene potenciado en la nueva axiología, la salud, una salud que es meramente animal, simple supervivencia, a la que se supeditan la libertad individual o la intimidad. Y cuando lo que sobrevive es vida sin cualificación humana, se podría pensar con Agamben: vida nuda, vida nula.

Echeverría y S. Almendros (2020, p. 447) observan que la implementación tecnológica y epidemiológica de la evolución del coronavirus se convirtió en una cuestión no solo principal, sino también tecno-política. Una eventual crisis de gestión sanitaria se convirtió de golpe en una crisis de salud pública. De modo que para afrontar el problema no sólo había que generar obediencia, sino también esperanza. Para ello, sin cuestionar el amparo "solucionista" tecnocientífico, se fueron marcando metas tecno-sanitarias por conseguir: por ejemplo, evitar el colapso del sistema hospitalario (de las UCl particularmente) y luego ir llegando al punto de inflexión de las

Revista de Comunicación y Salud, 2020, Vol. 10, nº 2, pp. 63-80 
curvas de contagio y fallecimientos, las cuales pasaron a convertirse en la auténtica representación tecno-científica del virus y su expansión: la meta suprema era "llegar al pico de la curva". Conforme la COVID-19 fue provocando con creciente virulencia la crisis sanitaria el control social fue el objetivo diana, así como impedir una ola de pánico social incontrolable (como el temor al desabastecimiento). Y todo para lograr un objetivo estratégico: generar una alarma social controlada, que se fue convirtiendo en tecnoCOVID-19 por ser parte de la infodemia ya referida.

No es de extrañar que, a partir de la vida despersonalizada como valor común y mayor que los valores individuales, los filósofos vean ocasión para proclamar el fracaso de la libertad de comercio o mercado, haciendo responsable al capitalismo tecno-liberal de los males de la pandemia, desde Žižek, que reinventa el comunismo como salida única a la crisis sanitaria, o Badiou, que afirma que la propagación del virus se debe a la elevación del capitalismo de estado chino a un rango imperial y anhela una tercera etapa el comunismo, a Han, quien, en "La emergencia viral y el mundo de mañana", teme la implantación de un estado policial digital en Occidente (ASPO, 2020, p. 110), o Harari, que teme el paso tecno-político de una vigilancia "epidérmica" a una vigilancia "hipodérmica" o Gabriel, para quien el orden mundial previo al virus ya era letal, pasando por Horvat, que ve en el virus un producto del capitalismo global, por Gray, que anuncia que la globalización neoliberal ha llegado a su fin y que ha llegado el momento para los estados nacionales y el comienzo de un mundo nuevo.

Desde el punto de vista filosófico, mucho más interesantes que las nostálgicas apelaciones al comunismo, por diferentes que sean, nos parecen las observaciones de Agamben cuando considera que el coronavirus no ha servido más que para decretar un estado de excepción injustificado, y las tesis biopolíticas de Esposito (2005, 2020b, 2020c), que quiere ir más allá señalando cómo con la pandemia se trastocan los papeles y tenemos a los políticos haciendo de médicos y a los médicos haciendo de políticos (2020a), y las tesis psicopolíticas de Han (2014), pues lo que hoy se busca disciplinar no es el cuerpo, sino la mente. El caso es que tanto una posición como la otra, por mucho que más o menos adrede, rivalicen sobre el mejor enfoque de la situación, de hecho, están enfatizando cómo la crisis sanitaria de la COVID-19 evidencia la intervención del poder (del poder del Estado, poder político, pero fundamentado tecno-científicamente, que si bien es cada vez menor frente a los tecnopoderes, que son poderes económicos, no obstante, ha resurgido y de modo manifiestamente autoritario, con independencia del refrendo o no parlamentario) en la vida humana. Y en su otra cara: la muerte. El estado de excepción normal o la biopolítica o la psicopolítica comportan el poder de dar la muerte, la tanatopolítica (Fernández Vítores, 2015) o "necropolítica" (Mbembe, 2003). Y como todas estas políticas se implementan hoy mediante esas nuevas maneras de ejercer el control social extendiendo el dominio digital sobre el mundo offline, que son las TIC, quedan todas ellas superadas por la tecnopolítica que es la forma político-social de la práctica del poder en el nuevo tiempo pandémico y que utiliza a tecno-personas, las cuales no solamente no son individuos, sino que tampoco son sujetos políticos, para controlar y someter a las personas. En los tecno-hospitales se ha estado decidiendo sobre la vida o la muerte de personas, priorizando la salvación de los jóvenes en detrimento de los 
viejos. He ahí el poder y su más vieja prerrogativa: la de dar la muerte. En la crisis del coronavirus la muerte lleva mascarilla, se la ponen los gobiernos que técnicamente la administran.

\section{CONCLUSIONES}

Una reflexión final se impone: desvanecida la "realidad" normal [Epígrafe 2], desmayada la "subjetividad" (disminución del sujeto epistémico [Epígrafe 3], así como el sujeto político [Epígrafe 4]), bajo la forma de la tecno-persona, el virus, tanto en su versión natural como, sobre todo, tecno-natural, configura el ejercicio de la vida en la época de la infopandemia y la "nueva normalidad". Tecno-COVID-19 ha convalidado la conversión de lo político-social (la gobernanza y la administración, el trabajo, la educación y hasta la sanidad) en tecno-política-social convirtiendo la excepción, lo onlife, en norma (la gobernanza y la administración, el trabajo, la educación y hasta la sanidad son en remoto). Los agentes y los pacientes político-sociales hodiernos pasan a ser funcionar como tecno-agentes y tecno-pacientes, tecno-personas de etiología tecno-vírica. La actividad viral tiene como escenarios los edificios de uso público, las calles y plazas, las playas y parques, los medios colectivos de transporte. Esa actividad en el límite tiende a cero, mediante la aplicación por los agentes gubernamentales de las tecnologías biopolíticas de disciplina social, de confinamiento doméstico, sobre todo, con instrumentos jurídicos de excepción penalizadores de toda desobediencia, siendo absorbida por la actividad tecno-viral, que tiende a infinito, en sus tecno-escenarios propios mayoritariamente online, mediante las nefelibatas tecnologías de la información y la comunicación, que presionan las mentes para interiorizar policialmente los datos y las discretas explicaciones oficiales y de científica apariencia sobre la evolución y la nocividad del coronavirus, que bajan las defensas racionales a la vez que golpean a las emocionales. No es la crisis sanitaria vírica la que está transformando la normalidad de la vida en la calle, sino las acciones tecno-políticas tomadas para afrontarla, aun cuando el reproche se lo lleve el virus previamente tecno-personificado. De hecho, puede que el coronavirus COVID-19 pase, pero lo hará dejando tras de sí un buen ejemplo de lo que será lo (tecno) político-social en los años venideros. Seguramente superaremos la pandemia, pero a costa quizá de que la tecno-pandemia informacional definitivamente nos haya superado.

\section{REFERENCIAS}

Agamben, Giorgio (2006). La comunidad que viene. Valencia: Pretextos.

ASPO (2020). Sopa de Wuhan. Pensamiento contemporáneo en tiempos de pandemias. ASPO (Aislamiento Social Preventivo y Obligatorio).

Echeverría, Javier y Sánchez Almendros, Dolores (2020). Tecnopersonas. Cómo nos transforman las tecnologías. Gijón: Trea.

Esposito, Roberto (2005). Inmunitas. Protección y negación de la vida, Amorrortu, Buenos Aires. 
Consecuencias de una crisis sanitaria. Botiquín de ideas para comprender el coronavirus y su tecno-pandemia informacional

Esposito, Roberto (28 febrero, 2020a). I partiti e il virus: la biopolitica al potere. La Repubblica. Recuperado de https://bit.ly/3iNBglg

Esposito, Roberto (28 febrero, 2020b). Curati a oltranza. Antinomie. Recuperado de https://antinomie.it/index.php/2020/02/28/curati-a-oltranza/.

Esposito, Roberto (18 marzo, 2020c). II sistema immunitario di un Paese sono le sue istituzioni. L'Espresso. Recuperado de https://bit.ly/3h3ALsT

Fernández Vítores, Raúl (2015). Tanatopolítica: opúsculo sobre los dispositivos humanos posmodernos. Madrid: Páginas de Espuma.

Galbraith, James K. (18 marzo, 2020). The Mobilization That Must Start Now. The Nation. Recuperado de https://bit.ly/2PZcubG

Gray, John (12 abril, 2020). Adiós a la globalización, comienza un mundo nuevo. El País. Recuperado de https://bit.ly/3avGo0L

Han, Byung-Chul (2012). La sociedad del cansancio. Barcelona: Herder.

Han, Byung-Chul (2014). Psicopolítica. Barcelona: Herder.

Harari, Yuval Noah (20 marzo, 2020). The world after coronavirus. Financial Times. Recuperado de https://on.ft.com/310PWOi

Horvat, Srećko (16 febrero, 2020). Lo más contagioso es el miedo. El País. Recuperado de https://elpais.com/elpais/2020/02/14/ideas/1581676668 075823.html/.

Lledó, Emilio (28 marzo, 2020). Ojalá el virus nos haga salir de la caverna, la oscuridad y las sombras / Entrevistado por Pablo de Llano. El País. Recuperado de https://bit.ly/3iQVdxx

Mbembe, Acchile (2003). Necropolitics. Public Culture, 15(1), pp.11-40.

Morin, Edgar (12 marzo, 2020). Ce que nous dit le coronavirus. Liberation. Recuperado de https://bit.ly/3g4iLgT

Puig Punyet, Enric (2020). Cuerpos rotos. La digitalización de la vida tras la covid-19. Madrid: Clave intelectual.

Sztajnszrajber, Darío (29 marzo, 2020). Ojalá superemos esta pandemia y nos deje algún aprendizaje, pero soy pesimista / Entrevistado por Sebastián Feijoo. Tiempo Argentino. Recuperado de https://bit.ly/2Y68EC1 
Consecuencias de una crisis sanitaria. Botiquín de ideas para comprender el coronavirus y su tecno-pandemia informacional

Žižek, Slavoj (3 febrero, 2020a). Clear racist element to hysteria over new coronavirus. Russia Today. Recuperado de https://bit.ly/2PX3R1f

Žižek, Slavoj (27 marzo, 2020b). Todos somos hoy Julian Assange, encerrados y sin visitas / Entrevistado por Rebeca Yanke. El Mundo. Recuperado de https://bit.ly/3kR1tYg

\section{AUTOR}

\section{José Antonio Marín-Casanova}

Profesor Titular de Universidad en la Hispalense, desde 1990, de cuyo Departamento de Metafísica y Corrientes Actuales de la Filosofía, Ética y Filosofía Política ha sido Secretario (2013-16) y Director (2016-20). Es IP del Grupo PAIDI HUM-326 ("Ciencia, Tecnología, Sociedad, y Racionalidad Práctica"). Dirige la revista Argumentos de Razón Técnica desde 2004. Cuenta con casi 100 publicaciones (incluidas 20 traducciones del inglés, del italiano, del alemán y del francés), con 6 libros/SPI como autor exclusivo, 3 libros como co-autor, 4 libros internacionales como editor literario, más de 30 capítulos de libros, y varias docenas de artículos en revistas indexadas de Europa, América Latina y Anglosajona.

Sisius: https://investigacion.us.es/sisius/sis showpub.php?idpers=1608

Orcid ID: https://orcid.org/0000-0002-7197-8968

Google Scholar: https://scholar.google.com/citations?user=KxFM2wQAAAAJ

ResearchID: F-4380-2016

Dialnet: $\underline{102651}$ 